\title{
Perfil do Profissional Contábil: Habilidades, Competências e Imagem Simbólica
}

\author{
Accounting Professional Profile: Skills, Competencies and Symbolic Image
}

Perfil del Profesional Contable: Habilidades, Competencias e Imagen Simbólica

\section{Anderson de Oliveira Reis}

Bacharel em Ciências Contábeis e Mestrando em Administração pela Universidade Federal de Viçosa (UFV).

Professor na União de Ensino Superior de Viçosa (UNIVIÇOSA).

Endereço: Departamento de Administração e Contabilidade, Av. Peter Henry Rolfs, S/N, Campus Universitário

CEP: 36570-900 - Viçosa/MG - Brasil

E-mail: andersonccoufv@gmail.com

Telefone: + 55 (31) 86188319

\section{Gislaine Aparecida Santana Sediyama}

Mestre em Ciências Contábeis pela Universidade Federal de Minas Gerais (UFMG)

Endereço: Departamento de Administração e Contabilidade, Av. Peter Henry Rolfs, S/N, Campus Universitário

CEP: 36570-900 - Viçosa/MG - Brasil

E-mail: gislaine.santana@ufv.br

Telefone: + 55 (31) 86293026

\section{Vinicius de Souza Moreira}

Mestrando em Administração pela Universidade Federal de Viçosa (UFV)

Endereço: Departamento de Administração e Contabilidade, Av. Peter Henry Rolfs, S/N,

Campus Universitário

CEP: 36570-900 - Viçosa/MG - Brasil

E-mail: vinicius.souza@ufv.br

Telefone: + 55 (31) 8752-1368

\section{Camila Carolina Moreira}

Bacharel em Ciências Contábeis pela Universidade Federal de Viçosa (UFV)

Endereço: Departamento de Adm. e Contab., Av. Peter Henry Rolfs, S/N, Campus Universitário CEP: 36570-900 - Viçosa/MG - Brasil

E-mail:kmillakarol@hotmail.com

Telefone: + 55 (31) 38992886

Artigo recebido em 25/08/2014. Revisado por pares em 23/03/2015. Recomendado para publicação em 26/03/2015 por Sandra Rolim Ensslin (Editora Científica). Publicado em 29/05/2015. 


\title{
Resumo
}

O objetivo deste trabalho foi identificar e analisar, a partir da percepção dos discentes do curso de Ciências Contábeis, as principais construções sociais que os estudantes possuem em relação ao profissional contábil. O estudo foi realizado com amostra de 134 estudantes que se dispuseram a participar da pesquisa. Utilizou-se da técnica de evocação de palavras e de questões do tipo atitude por escala (associadas à escala Likert) para coleta de dados. Concluiuse que a representação social que os discentes formaram do profissional contábil foi de um profissional de comportamentos e condutas éticas, com amplos conhecimentos teóricos e práticos, responsabilidade nas suas ações e comprometimento com o seu trabalho. As habilidades e competências percebidas como as mais importantes foram habilidades intelectuais e do conhecimento, assim como as pessoais. $\mathrm{O}$ que poderia estar relacionado à forma como curricularmente o curso se estrutura.

Palavras chaves: Habilidades. Competências. Representação social. Profissional contábil.

\begin{abstract}
The aim of this study was to identify and analyze the main social constructions that students have in relation to accounting professionals, from the perception of Accounting Sciences Course learners. The study was conducted with a sample of 134 students who were willing to participate. We used the word remembrance and questions technique such as attitude scale (associated with Likert scale) for data collection. It was concluded that social representation that learners formed with regard to accounting professionals was that they own an ethical behavior and conduct, with wide theoretical and practical knowledge, responsibility for their actions and commitment to their work. The skills and abilities perceived as the most important were the intellectuals and knowledge as well as the personal ones, what could be related to how the course is structured in terms of curriculum.
\end{abstract}

Keywords: Skills. Abilities. Social representation. Accounting professional.

\section{Resumen}

El objetivo de este trabajo fue identificar y analizar, a partir de la percepción de los discentes del curso de Ciencias Contables, las principales construcciones sociales que los estudiantes poseen en relación al profesional contable. El estudio fue realizado con muestra de 134 estudiantes que se dispusieron a participar del estudio. Fue utilizada la técnica de evocación de palabras y de cuestiones como actitud por escala (asociadas a la escala Likert) para recopilación de datos. Se llegó a la conclusión que la representación social que los discentes formaron a respecto del profesional contable fue la de un profesional de comportamientos y conductas éticas, con amplios conocimientos teóricos y prácticos, responsabilidad en sus acciones y comprometimiento con su trabajo. Las habilidades y competencias percibidas como las más importantes fueron habilidades intelectuales y de conocimiento, así como las personales. Lo que podría estar relacionado a la forma como curricularmente el curso es estructurado.

Palabras clave: Habilidades. Competencias. Representación social. Profesional contable. 


\section{Introdução}

A ênfase dada à Contabilidade e a profissão de contador tem mudado nos últimos anos. As mudanças ocasionadas pela adoção das normas internacionais de contabilidade pelo Brasil proporcionaram alteração não só nas normas e procedimentos contábeis, mas também na forma de atuação dos contadores.

Nesse processo, o profissional contábil passou a ser visto como "oportunidade de negócio", ou seja, um diferencial para a administração das empresas na medida em que deixa de cumprir apenas com as obrigações acessórias e passa a participar mais ativamente do processo gerencial das organizações (LEAL; SOARES; SOUSA, 2008). Com isso, as exigências acerca da formação do profissional contábil se ampliaram.

As alterações ocorridas nos últimos anos na atuação do profissional contábil decorrente, dentre outros fatores, da globalização e das inovações em tecnologia da informação, levaram os profissionais a buscarem formas de desenvolverem suas competências e de adquirirem novas habilidades e conhecimentos (MOHAMED; LASHINE, 2003).

Ott et al. (2011) relatam que tais mudanças justificam a preocupação com as demandas do mercado e da sociedade, exigindo novas qualificações para a atuação do profissional contábil. Tais exigências implicam na qualificação profissional quanto às competências, $o$ conhecimento, as habilidades e atitudes, requerendo, desse modo, um novo perfil do profissional contábil, que esteja mais preparado para enfrentar a atual realidade das organizações.

Essas discussões no âmbito acadêmico apontam a importância do desenvolvimento de habilidades e competências para o bom desempenho da profissão, visto que, um profissional de valor precisa mais que acumular conhecimentos teóricos.

Para Schlindwein (2007), o moderno profissional da contabilidade precisa desenvolver diferentes habilidades como iniciativa, coragem, ética, visão de futuro, negociação, agilidade, segurança para solucionar problemas, tem que ser dinâmico, flexível e com boa capacidade de inovar e criar, sobretudo na sua área de atuação.

As diretrizes curriculares instituídas pelo Conselho Nacional de Educação (CNE) de $\mathrm{n}^{\circ}$ 10/2004 propuseram às Instituições de Ensino Superior (IES) determinadas habilidades e competências para formação do bacharel em Ciências Contábeis, com conhecimentos abrangentes que vão desde a comunicação ao desenvolvimento de sistemas de informação contábil.

Assim, neste novo contexto de atuação do contador, as Instituições do Ensino Superior são responsáveis pela formação dos profissionais dotados de competências necessárias para suprir as demandas dos usuários das informações contábeis e que irão atuar em diferentes áreas, como: auditoria, finanças, controladoria, planejamento tributário, contabilidade societária, perícias, custos entre outros (PIRES; OTT; DAMACENA, 2010).

Nesse sentido, torna-se relevante questionar: qual é a percepção dos discentes do curso de Ciências Contábeis com relação às habilidades e competências necessárias para a atuação do profissional contábil?

No intuito de captar a percepção dos discentes, adotar-se-á os preceitos da Teoria das Representações Sociais (TRS) que se mostra adequada, pois as representações são construídas por meio de senso comum e da consciência coletiva que vão se transformando de simples opiniões para verdades subjetivas. Estas construções visam simplificar a complexidade do objeto, facilitando a comunicação e a orientação de condutas. Essas verdades ajudam a criar a 
identidade grupal e o sentimento de pertencimento do indivíduo ao grupo (ALVESMAZZOTTI, 2008).

Com isso, o objetivo deste trabalho foi identificar e analisar, a partir da percepção dos discentes do curso de Ciências Contábeis, as principais construções sociais que os estudantes possuem em relação à profissão contábil.

O curso de ciências contábeis tomado por base para estudo é oferecido por uma Instituição pública de Ensino Superior situada no estado de Minas Gerais. A estrutura curricular do curso seguem as Diretrizes Curriculares Nacionais presentes na Resolução CNE/CES no 10/2004, para formação de um bacharel em Ciências Contábeis. No entanto, inova ao permitir o estudante escolher, dentre um rol de disciplinas optativas e facultativas, aquelas que estariam mais aderentes ao perfil profissional que pretende construir para si. Além disso, permite que o estudante, por meio de convênio firmado pela instituição com outras instituições públicas de ensino superior do país e do exterior, realizar mobilidade acadêmica. Para tanto há procedimentos específicos que o estudante deve atender.

O curso em análise tem duração de quatro anos e meio, podendo se estender até sete anos e meio. É dividido em semestres, logo o estudante tem que cumprir, pelo menos, nove semestres para obtenção do título de bacharel em ciências contábeis. Traz em sua estrutura disciplinas de caráter obrigatório, optativo e facultativo. As optativas compõem um grupo de disciplinas de outras áreas do conhecimento como administração, economia, engenharia da produção, matemática, sociologia e educação, que são sugeridas ao estudante. As facultativas são disciplinas que o estudante pode cursar em qualquer outra área do conhecimento que ele julgue ser relevante ao desempenho de suas atividades enquanto profissional contábil. Estas disciplinas são devidamente validadas pela instituição.

Para estimular a multidisciplinariedade, é possibilitado ao estudante cursar a partir do $5^{\circ}$ período disciplinas de carácter optativo e facultativo, além daquelas obrigatórias definidas para o período. É válido ressaltar que o estudante tem sempre que cursar disciplinas obrigatórias consideradas essenciais à sua formação de contador.

Este estudo se justifica por permitir compreender o olhar que os discentes conferem à profissão que irão exercer, além de revelar se a estrutura curricular do curso pode, assim como a infusão de valores e conhecimentos feitos pelos professores ao longo do curso, provocar modificações na imagem simbólica que ele tem das habilidades e competências que precisa desenvolver para o exercício de sua profissão. Além disso, denotaria a política educacional adotada por parte da instituição em estudo que está mais voltada para a autonomia, flexibilidade e responsabilidade do discente na escolha do perfil profissional que pretende construir para si, além daquele fundamental que se faz mister desenvolver para atuação enquanto contador.

Além desta introdução, o artigo traz em seguida uma incursão teórica sobre as habilidades e competências requeridas para o exercício da profissão contábil e a teoria da representação social. Após, são apresentados os procedimentos metodológicos e a análise e discussão dos resultados. Ao final, apresenta-se a conclusão juntamente com a contribuição do estudo e de sugestão para estudos futuros. 


\section{Referencial Teórico}

\subsection{Habilidades e Competências}

Cardoso, Riccio e Albuquerque (2009, p. 366) destacam que "o termo competência tem origem no latim competentia significando a qualidade de quem é capaz de apreciar e resolver certo assunto, de fazer determinada coisa, com capacidade, habilidade, aptidão e idoneidade".

Para Fleury e Fleury (2004, p. 30), competência pode ser definida como sendo "um saber agir responsável e reconhecido, que implica mobilizar, integrar, transferir conhecimentos, recursos, habilidades, que agreguem à organização e social ao indivíduo". É a capacidade de desempenhar um papel obedecendo a um determinado padrão de referência (IFAC, 2010).

Dutra (2004) considera que as competências necessárias de um profissional podem ser previstas e estruturadas de maneira a estabelecer um conjunto ideal de conhecimentos, qualificações técnicas, valores e atitudes éticas que se desenvolvidas oferecem performance superior ao trabalho.

O termo habilidade tem como origem a palavra habilitate, do latim, que significa saber fazer. É a capacidade do indivíduo de realizar algo, como classificar, montar, calcular, ler, observar e interpretar (CARDOSO et al., 2011).

Para Gomes (2003) identificar variáveis, compreender fenômenos, relacionar informações, analisar situações-problema, sintetizar, julgar, correlacionar e manipular são exemplos de habilidades.

No Brasil, as habilidades e competências necessárias para o desenvolvimento da profissão contábil estão disponíveis na Resolução CNE/CES n¹0/2004 que instituem as diretrizes curriculares do curso de Ciências Contábeis para as Instituições de Ensino Superior.

Já no cenário norte-americano, segundo Ott et al. (2011), a entidade American Institute of Certified Public Accountants (AICPA) organizou o Core Competency Framework (AICPA, 2010), que propõe um modelo de competências padrão que devem ser desenvolvidas pelos profissionais em sua inserção no mercado de trabalho. No contexto da convergência aos padrões internacionais, o International Education Standard 3 (IFAC, 2010), também, relaciona as habilidades que devem ser desenvolvidas pelo profissional contábil (OTT et al., 2011). No Quadro 1 sumariza-se as competências em âmbito internacional. 
Anderson de Oliveira Reis, Gislaine Aparecida S. Sediyama, Vinicius de Souza Moreira e Camila C. Moreira

Quadro 1 - Competências em âmbito internacional

\begin{tabular}{|c|c|c|}
\hline \multirow{4}{*}{$\begin{array}{l}\text { American } \\
\text { Institute of } \\
\text { Certified } \\
\text { Public } \\
\text { Accountants } \\
\text { (AICPA, } \\
\text { 2010) }\end{array}$} & Competências & Descrição \\
\hline & $\begin{array}{l}\text { Competências } \\
\text { funcionais }\end{array}$ & $\begin{array}{l}\text { Corresponde às competências técnicas, capacidade de executar análise } \\
\text { crítica, avaliar e fornecer dados, desenvolver, analisar e implementar } \\
\text { sistemas de informação contábil e de controle gerencial; }\end{array}$ \\
\hline & $\begin{array}{l}\text { Competências } \\
\text { pessoais }\end{array}$ & $\begin{array}{l}\text { São a comunicação, os comportamentos e atitudes que contribuem para } \\
\text { forma como indivíduos se relacionam com os demais e facilidade de } \\
\text { aprendizagem individual; }\end{array}$ \\
\hline & $\begin{array}{l}\text { Competências } \\
\text { relacionadas aos } \\
\text { negócios }\end{array}$ & $\begin{array}{l}\text { São o conhecimento e compreensão sobre o ambiente interno e externo } \\
\text { dos negócios e das organizações. }\end{array}$ \\
\hline \multirow{7}{*}{$\begin{array}{c}\text { International } \\
\text { Education } \\
\text { Standard - } \\
\text { IES } 3 \\
\text { (IFAC, 2010) }\end{array}$} & Competências & Descrição \\
\hline & Intelectuais & $\begin{array}{l}\text { Contribuem para solucionar problemas, tomar decisões e julgar situações } \\
\text { complexas, assim como está relacionada ao conhecimento e entendimento } \\
\text { cognitivo; }\end{array}$ \\
\hline & $\begin{array}{l}\text { Técnicas e } \\
\text { funcionais }\end{array}$ & $\begin{array}{l}\text { Compreendem as habilidades gerais e específicas de contabilidade, assim } \\
\text { como a matemática, estatística e conhecimento em tecnologia da } \\
\text { informação; }\end{array}$ \\
\hline & Pessoais & $\begin{array}{l}\text { Compreendem as atitudes e comportamentos do profissional contábil que } \\
\text { proporcionam melhoria na sua aprendizagem pessoal e profissional, assim } \\
\text { como o comportamento ético e o auto-apredizado. }\end{array}$ \\
\hline & $\begin{array}{l}\text { Interpessoais e de } \\
\text { comunicação }\end{array}$ & $\begin{array}{l}\text { Permitem que o profissional interaja com outras áreas de conhecimento, } \\
\text { trabalhe em equipe, receba e transmita informações, forme julgamentos, } \\
\text { tome decisões; }\end{array}$ \\
\hline & $\begin{array}{l}\text { Organizacionais e } \\
\text { de gerenciamento } \\
\text { de negócios }\end{array}$ & $\begin{array}{l}\text { São as habilidades relacionadas ao funcionamento da organização, } \\
\text { planejamento estratégico e gestão de processo; }\end{array}$ \\
\hline & Conhecimentos & $\begin{array}{l}\text { São as habilidades relacionadas aos conhecimentos específicos da } \\
\text { contabilidade, como finanças e áreas afins, acerca dos negócios e das } \\
\text { organizações e sobre a tecnologia da informação. }\end{array}$ \\
\hline
\end{tabular}

Fonte: AICPA (2010); IFAC (2011).

Pesquisas nacionais e internacionais demonstram a importância de estudos voltados à compreensão do perfil, habilidades e competências dos profissionais contábeis. Cory e Huttenhoff (2011) discutem quais os tópicos mais importantes a serem abordados nos cursos de graduação em Ciências Contábeis buscando identificar quais habilidades e competências são priorizadas na formação dos contadores nos Estados Unidos. O estudo foi realizado com 170 contabilistas empregados em empresas privadas de porte médio, que concluíram que as habilidades mais importantes para o desenvolvimento da profissional contábil foram o pensamento crítico, comunicação escrita e oral e relacionamento interpessoal. E os tópicos mais importantes na graduação foram a contabilidade intermediaria, ética, contabilidade avançada, gerencial, auditoria e contabilidade tributária.

Ott et al. (2011) compararam a percepção de estudantes de cursos de Ciências Contábeis, em Instituições de Ensino Superior brasileiras com as de profissionais da Contabilidade, quanto aos conhecimentos, às habilidades e aos métodos de ensinoaprendizagem considerados como mais importantes para a atuação do contador no mercado de trabalho. A amostra do estudo contou com 1.710 participantes, sendo parte desses estudantes de graduação e contadores registrados nos Conselhos Regionais de Contabilidade em diferentes regiões. Os resultados obtidos foram comparados com pesquisas internacionais da

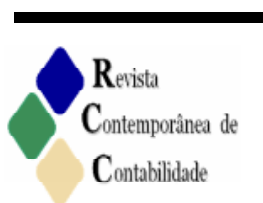

ISSN 2175-8069, UFSC, Florianópolis, v. 12, n. 25, p. 95-116, jan./abr. 2015 
China e dos Estados Unidos, mostrando que os escores dos profissionais brasileiros são sempre maiores para as três dimensões (conhecimentos, habilidades e métodos) quando comparado com os dois países.

A Resolução CNE/CES no 10/2004, do curso de graduação de Ciências Contábeis, evidencia quais são as habilidades e competências inter e multidisciplinares necessárias para a formação do profissional. São elas, conforme art. $4^{\circ}$ desta mesma resolução,

I - utilizar adequadamente a terminologia e a linguagem das Ciências Contábeis e Atuariais;

II - demonstrar visão sistêmica e interdisciplinar da atividade contábil;

III - elaborar pareceres e relatórios que contribuam para o desempenho eficiente e eficaz de seus usuários, quaisquer que sejam os modelos organizacionais;

IV - aplicar adequadamente a legislação inerente às funções contábeis;

$\mathrm{V}$ - desenvolver, com motivação e através de permanente articulação, a liderança entre equipes multidisciplinares para a captação de insumos necessários aos controles técnicos, à geração e disseminação de informações contábeis, com reconhecido nível de precisão;

VI - exercer suas responsabilidades com o expressivo domínio das funções contábeis, incluindo noções de atividades atuariais e de quantificações de informações financeiras, patrimoniais e governamentais, que viabilizem aos agentes econômicos e aos administradores de qualquer segmento produtivo ou institucional o pleno cumprimento de seus encargos quanto ao gerenciamento, aos controles e à prestação de contas de sua gestão perante a sociedade, gerando também informações para a tomada de decisão, organização de atitudes e construção de valores orientados para a cidadania;

VII - desenvolver, analisar e implantar sistemas de informação contábil e de controle gerencial, revelando capacidade crítico analítica para avaliar as implicações organizacionais com a tecnologia da informação;

VIII - exercer com ética e proficiência as atribuições e prerrogativas que lhe são prescritas através da legislação específica, revelando domínios adequados aos diferentes modelos organizacionais.

Nota-se, portanto, uma convergência existente entre as diretrizes curriculares nacionais do curso de Ciências Contábeis com as dos órgãos internacionais.

\subsection{Teoria das Representações Sociais}

A Teoria das Representações Sociais (TRS) surgiu no final da década de 1950 a partir de estudos realizados por Serge Moscovici, publicados no ano de 1961. Moscovici trouxe em seus trabalhos uma nova percepção a respeito da integração entre os fenômenos perceptivos individuais e sociais.

As teorias existentes à publicação do trabalho seminal da Teoria das Representações Sociais estabeleciam uma extinção entre dois fenômenos: o individual e o coletivo. Durkheim, um dos predecessores de Moscovici, percebia a representação coletiva como dois campos separados de estudos: o individual seria o foco da psicologia e o coletivo o foco da sociologia (FARR, 2002).

Moscovici, por outro lado, propôs a junção do individual com o coletivo, e substituiu o termo "coletivo" por social, com o propósito de enfatizar a diferenciação de redes de pessoas e suas interações (FERREIRA, 2005). Sendo assim, "qualquer crença, ideia ou emoção presente na sociedade, era considerada uma representação" (MAGALHÃES; MAIA, 2009, p.195). 
A contribuição que Moscovici apresentou foi uma nova forma de entendimento das relações, em termos de construções, interpretações de significados, dos indivíduos com a sociedade (VERGARA; FERREIRA, 2005). De acordo com Moscovici (1978, p.28), "a representação social é uma modalidade de conhecimento particular que tem por função a elaboração de comportamentos e a comunicação entre indivíduos". São fenômenos que possuem caráter dinâmico, logo são formas de conhecimento de vida cotidiana que servem tanto para os indivíduos compreenderem quanto para se comunicarem (MOSCOVICI, 2003).

Para Jodelet (2001, p. 17), as representações sociais são "uma modalidade de conhecimento socialmente elaborada e partilhada, com um objetivo prático e contribuindo para a construção de uma realidade comum a um conjunto social", sendo usualmente designadas por senso comum.

A representação de determinado objeto não se constrói isoladamente, ela se articula com as informações que se relacionam com outras, surgindo à experiência com aquele objeto que se relaciona ao sujeito (JODELET, 2001). Desta forma, as representações são dinâmicas, ou seja, produzem comportamentos e influenciam relacionamentos, englobando ações que se modificam umas às outras.

Não são meras reproduções, tampouco reações a estímulos exteriores determinados; antes, são sistemas que possuem uma lógica própria, uma linguagem particular e uma estrutura que tem como base tanto valores quanto conceitos (FERREIRA, 2005). Não são simples opiniões a respeito de algo ou imagens de algum objeto. São verdadeiras teorias construídas coletivamente, destinando-se à interpretação e à construção da realidade (MOSCOVICI, 2004).

Uma representação social pode também ser definida como um conjunto de percepções, imagens, opiniões, crenças e atitudes mantidas por um determinado grupo. Permite investigar como se formam e funcionam os sistemas de referência que se tem utilizado para classificar pessoas e grupos para interpretar os acontecimentos da realidade da vida cotidiana (ALVESMAZZOTTI, 2008). As relações estabelecidas entre esses elementos induzem os indivíduos que compartilham de uma dada representação, à atribuição de significados próprios a fenômenos sociais (VERGARA; FERREIRA, 2005).

O processo de construção de uma representação social se dá de várias formas, sendo influenciado pelas interações humanas formais e informais que ocorrem nas diversas instituições, grupos sociais, pelos meios de comunicação de massa e pelos movimentos sociais organizados (JOVCHELOVITCH, 1995). São construídas mais no âmbito do universo consensual, pois são construídas através da reprodução da realidade, como uma tradução ou interpretação que se faz a partir do contexto social que o individuo está inserido, resultantes do saber da comunidade (senso comum) (MUNHOZ, 2010).

$\mathrm{O}$ ato de representar não é um processo simples, além da imagem há sempre um sentido simbólico. Uma representação social sempre é de alguma coisa (objeto) e de alguém (sujeito), tendo como seu objeto uma relação de simbolização e de interpretação. A representação é apresentada como uma forma de saber e de conhecimento, pois modeliza o objeto diretamente legível em diversos suportes linguísticos, comportamentais ou materiais. Também diz que qualificar esse saber prático se refere à experiência a partir da qual ele é produzido, aos contextos e condições em que ele o é e, sobretudo, ao fato de que a representação serve para agir sobre o mundo e os outros (JODELET, 2001). 
Para Moscovici (1978), sujeito e objeto não são funcionalmente distintos, eles formam um par inseparável. Isso quer dizer que um objeto não existe sozinho, mas sim em relação a um sujeito (indivíduo ou grupo), logo, precisa haver uma relação sujeito-objeto para que se determine o próprio objeto.

Ao formar uma representação de um objeto, o sujeito, de alguma forma, o constitui, o reconstrói em seu sistema cognitivo, de modo a adequá-lo aos seus conhecimentos e valores, o qual depende do contexto social e do histórico no qual o individuo está inserido (CRAMER; BRITO; CAPPELLE, 2001; MAZZOTTI, 2001).

A Figura 1 apresenta um esquema simplificado da construção da representação social de um objeto pelo sujeito definido por Jodelet (1989).

Figura 1 - Construção da imagem simbólica de um objeto

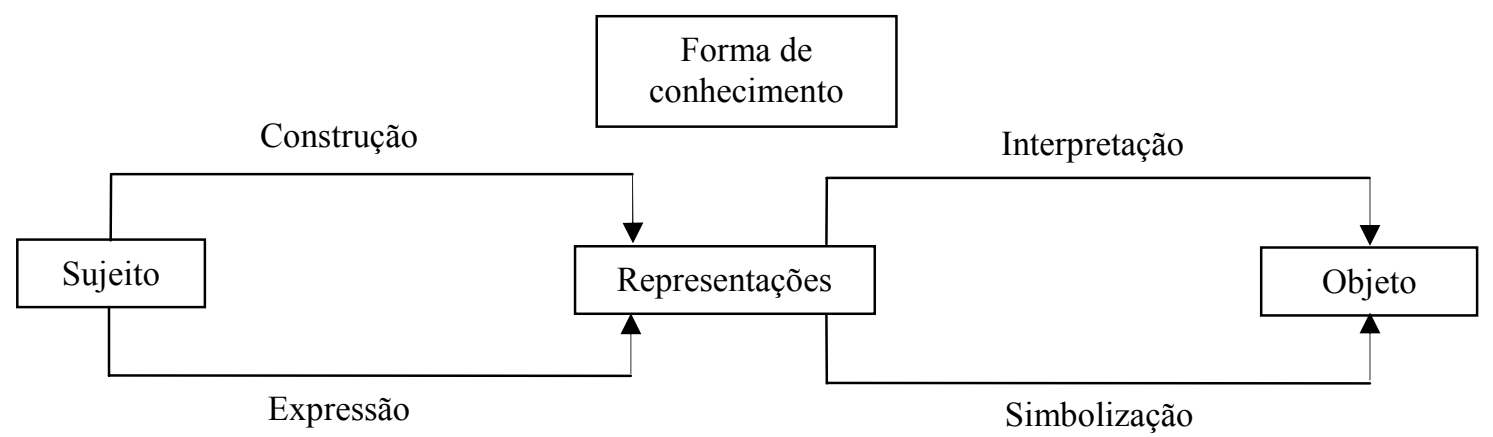

Fonte: Spink (1993).

A construção da imagem simbólica de um dado objeto é feita por duas vias, sendo uma pela construção e a outra pela expressão. A construção constitui formas de conhecimento prático orientadas para compreensão do mundo e para a comunicação (SPINK, 1993), ou seja, reflete o conhecimento consensual que os indivíduos fazem do objeto através interações informais e da vida cotidiana. A expressão emerge como elaborações (construções de caráter expressivo) de sujeitos sociais a respeito de objetos socialmente valorizados (SPINK, 1993), ou seja, retrata o conhecimento prático construído pelo sujeito a partir daquilo que é socialmente aceito (SANTANA et al., 2013).

Nesse sentido, ao se adotar determinado objeto para análise o sujeito, fundamentado em seu conhecimento adquirido a partir de suas interações sociais em seu cotidiano (senso comum) e suas percepções, crenças e valores acerca daquele objeto, interpreta esses conceitos e cria-se uma imagem simbólica consciente do que é verdadeiramente o objeto ou de como o indivíduo gostaria que ele fosse (SANTANA et al., 2013).

Para Moscovici (2004) as representações sociais devem ser vistas como uma forma de compreender e transmitir o que já se sabe e que resultam em esforços de tornar algo incomum ou não familiar em algo comum e real, ou seja, de tornar familiar o não familiar. Se formam a partir das relações entre sujeitos sociais, por meio de dois processos sociocognitivos: ancoragem e objetivação.

A ancoragem diz respeito aos processos de classificação e rotulação, os quais implicam o estabelecimento de uma rede de significações em torno do objeto, relacionando-o a valores e práticas sociais partilhadas pelo grupo (MAGALHÃES; MAIA, 2009). Busca nas 
representações pré-existentes uma forma de classificá-las, trazendo para um contexto conhecido (ALVES-MAZZOTTI, 2008).

A ancoragem é o processo que dá sentido ao objeto representado, que transforma algo desconhecido em familiar através da inclusão num sistema de categorias, ao compará-lo com os critérios de uma dada categoria. A ancoragem demostra o modo como o social intervém no objeto representado que precede na busca da familiarização que ocorrem tanto em relação ao indivíduo quanto ao grupo social que pertencem (MUNHOZ, 2010).

A objetivação se refere às informações e noções relativas ao objeto que são filtradas, condensando-se em imagens ou esquemas (MAGALHÃES; MAIA, 2009). Transforma conceitos em algo concreto, liga uma palavra ou ideia a uma imagem (ALVES-MAZZOTTI, 2008).

$\mathrm{Na}$ objetivação, o objeto "estranho" vai se transformando de acordo com possibilidades do grupo; se tornando algo objetivo, concreto, familiar, materializado e estruturado (FERREIRA, 2005).

A ancoragem e a objetivação estão dialeticamente ligadas uma a outra, através da comunicação entre os indivíduos de um determinado grupo social, que articulam as três funções básicas de uma representação: familiarização com a novidade, interpretação da realidade, orientação de condutas e das relações sociais (JODELET, 2001).

$\mathrm{O}$ núcleo central de uma representação social resultante do processo de objetivação e ancoragem corresponde ao sistema de valores ao qual se refere o sujeito, isto é, traz a marca da cultura e das normas sociais de seu ambiente (MAGALHÃES; MAIA, 2009). O núcleo central gera o significado da representação, determina sua organização e a estabiliza (ABRIC, 2008).

Segundo Magalhães e Maia (2009, p.196) “é em torno desse núcleo que se constitui o conjunto da representação que fornece o quadro de categorização e de interpretação de novas informações; os outros elementos vão ser retidos, categorizados e interpretados em função de sua natureza".

Nem todo objeto ou fenômeno social constitui uma representação (FERREIRA, 2005). É preciso que se tenha relevância cultural na comunidade ou grupo para que se possa formar uma representação social, pois alguns objetos trazem apenas opiniões e imagens desconexas. Por isso que não há o porquê de existir uma representação social para cada objeto que se possa imaginar (FERREIRA, 2005). Desta forma, é possível que um determinado grupo tenha uma representação de certo objeto enquanto outros apresentem apenas opiniões, informações e imagens sobre o mesmo objeto (SÁ, 1998).

\section{Procedimentos Metodológicos}

\subsection{Classificação da Pesquisa e Coleta de Dados}

A presente pesquisa caracteriza-se como descritiva, de natureza qualitativa e quantitativa e visa descrever e analisar a percepção dos discentes do curso de Ciências Contábeis de uma IES do estado de Minas Gerais quanto a habilidades e competências necessárias para o exercício da profissão contábil. 
A população abrange os estudantes matriculados no segundo semestre de 2013 do curso de Ciências Contábeis, de diferentes períodos, da referida IES, somando no total 193 estudantes.

O estudo foi realizado com amostra de 134 estudantes que se dispuseram a participar da pesquisa. Assim, a amostra configura-se como não probabilística e formada pelo critério de acessibilidade. Os dados, origem primária, foram coletados entre novembro/2013 e janeiro/2014.

Utilizou-se da técnica de evocação de palavras, que conforme Vergara (2010), trata-se do método de coleta de dados que solicita aos indivíduos pesquisados que mencionem, oralmente ou por escrito, palavras que lhe vem à cabeça, a partir da evocação, pelo pesquisador, de uma expressão indutora.

A expressão indutora utilizada referia à atuação do profissional contábil. Foi solicitado aos discentes que escrevessem as primeiras palavras que lhe vinham à cabeça quando ouvissem a expressão "habilidades e competências necessárias para atuação do profissional contábil".

Para medir as variáveis que constituíam atitudes por escala foram utilizadas questões escala do tipo Likert, que consiste em um conjunto de itens apresentados em forma de afirmações ou juízos perante os quais se pede a reação dos indivíduos (SAMPIERI; COLLADO; LUCIO, 2006). As afirmações qualificam o objeto de atitude que está sendo medido e devem expressar apenas uma relação lógica (SAMPIERI; COLLADO; LUCIO, 2006).

A forma de aplicação utilizada foi a de maneira "auto-administrada" (SAMPIERI; COLLADO; LUCIO, 2006, p.315), onde o pesquisador entrega a escala ao indivíduo e este marca, com relação a cada afirmação, a categoria que melhor descreve sua reação ou resposta. A questão com o método de evocação de palavras foi a primeira a ser apresentada aos respondentes de modo que os conteúdos apresentados na escala tipo Likert não influenciassem as demais respostas.

A afirmativa utilizada na escala tipo Likert da pesquisa se fundamentou na importância atribuída pelo respondente às habilidades e competências necessárias para formação do profissional contábil exigidas pela Resolução do CNE/CES n ${ }^{\circ} 10 / 2004$ do curso de ciências contábeis. As questões variavam de 1="Não é Importante", 2="Pouco Importante", 3="Importante", 4="Muito Importante", 5="Indispensável".

\subsection{Tratamento e Forma de Apresentação dos Dados}

Os dados de natureza qualitativa, referentes ao teste de evocação de palavras foram tabulados utilizando como apoio do MS Excel. Logo após foi calculado a frequência de cada palavra evocada no intuito de descrever a representação social que os discentes possuem com relação às habilidades e competências da profissão contábil.

Os dados, de natureza quantitativa, foram analisados por meio de procedimentos estatísticos manipulados no programa Statistical Package for the Social Sciences (SPSS) v. 20.0® e MS Excel, a partir da utilização da Estatística Descritiva, do Alfa de Cronbach, do Teste Kolmogorov-Smirnov (K-S) e o do teste U de Mann-Whitney.

As questões do tipo atitude por escala foram subdividas em quatro dimensões, sendo elas: Habilidades e Competências Técnicas e Funcionais; Habilidades e Competências 
Pessoais; Habilidades Intelectuais e do Conhecimento; e Habilidades e Competências Organizacionais e Relação Interpessoal.

As dimensões foram elaboradas com base no artigo 4 da resolução CNE/CES n ${ }^{\circ}$ 10/2004 e nas normas do IES 3 (IFAC, 2010) e AICPA (2010), onde constam as habilidades e competências necessárias para o profissional contábil.

No Quadro 2 apresenta-se os conceitos utilizados para construir as dimensões estudadas e as respectivas variáveis componentes.

Quadro 2 - Conceituação das Dimensões

\begin{tabular}{|c|c|}
\hline Dimensão & Descrição e Variáveis \\
\hline $\begin{array}{l}\text { Habilidades e } \\
\text { Competências } \\
\text { Técnicas e } \\
\text { Funcionais }\end{array}$ & $\begin{array}{l}\text { Corresponde as habilidades gerais e específicas da contabilidade, como as competências } \\
\text { técnicas (análise de risco, mensuração, relatórios). Terminologia contábil, terminologia } \\
\text { atuária, domínio contábil, noções atuárias, desenvolver informação, analisar informação } \\
\text { e implantar informação. }\end{array}$ \\
\hline $\begin{array}{l}\text { Habilidades e } \\
\text { Competências } \\
\text { Pessoais }\end{array}$ & $\begin{array}{l}\text { Corresponde aos comportamentos e atitudes do profissional contábil que proporcionam } \\
\text { melhoria no relacionamento profissional e aprendizado individual. Liderança de } \\
\text { captação, liderança de disseminação, ética, atividades complementares, práticas de } \\
\text { estudo e práticas na comunidade. }\end{array}$ \\
\hline $\begin{array}{l}\text { Habilidades } \\
\text { Intelectuais e do } \\
\text { Conhecimento }\end{array}$ & $\begin{array}{l}\text { Corresponde as atribuições para solucionar problemas, tomar decisões, julgar situações } \\
\text { complexas e conhecimentos em contabilidade e áreas afins (contabilidade financeira, } \\
\text { gerencial, auditoria entre outros) e relacionados aos negócios. Visão sistêmica, } \\
\text { legislação, informações patrimoniais, crítico - analítico, legislação específica, } \\
\text { conhecimento econômico, normas internacionais e questões científicas. }\end{array}$ \\
\hline $\begin{array}{l}\text { Habilidades e } \\
\text { Competências } \\
\text { Organizacionais e } \\
\text { Relação Interpesso: }\end{array}$ & $\begin{array}{l}\text { Compreende o entendimento do ambiente interno e externo dos negócios e as } \\
\text { habilidades relacionadas ao funcionamento da organização. Interação com outras áreas } \\
\text { de conhecimento, receber e transmitir informações, formar julgamentos e tomar } \\
\text { decisões. Gerenciamento, tomada de decisão, construção de valores, modelos } \\
\text { organizacionais, organizações públicas, organizações privadas e terceiro setor. }\end{array}$ \\
\hline
\end{tabular}

Fonte: Elaborado pelos autores com base na CNE/CES nº 10/2004, IFAC (2010) e AICPA (2010).

Para análise de cada dimensão, utilizou-se a estatística descritiva que, segundo Fávero et al. (2009), permite compreender melhor o comportamento dos dados por meio de tabelas, gráficos e medidas-resumo, identificando tendências, variabilidades e valores atípicos. Especificamente, fez-se uso de medidas de posição (média aritmética), medidas de dispersão (desvio padrão) e distribuição de frequências.

Com o intuito de verificar a confiabilidade das dimensões estabelecidas utilizou-se a técnica do Alfa de Cronbach que se trata de uma ferramenta estatística que visa à validação dos constructos em que as variáveis componentes são fortemente correlacionadas (HAIR et al., 2005). A confiabilidade de um teste é a constância ou estabilidade dos resultados que proporciona um instrumento de medida (BISQUERRA; SARRIERA; MARTÍNEZ, 2004).

A técnica do Alfa de Cronbach permite valores no intervalo de 0 a 1 , sendo que, valores baixos indicam que os itens utilizados na escala não medem adequadamente o constructo utilizado. Na literatura existem várias sugestões de corte para a validação de um constructo, sendo 0,60 o valor mínimo recomendado por Hair et al. (2009).

Cada dimensão estudada é composta por um conjunto de variáveis, cujos valores foram somados, apurando-se a média dos escores de cada dimensão. Tal abordagem, conhecida como Escala Somada, tem como vantagens "facilitar a comparação dos grupos e 
compreensão de suas diferenças. Desta forma, várias afirmações são somadas para formar um escore total para um constructo" (HAIR et al., 2005, p.199).

Dois grupos de estudantes foram estabelecidos: (1) graduandos em Ciências Contábeis que estavam no $2^{\circ}$ e $4^{\circ}$ períodos, denominados de iniciantes; e (2) graduandos em Ciências Contábeis que estavam no $6^{\circ}$ e $8^{\circ}$ períodos, denominados concluintes.

Para avaliar as diferenças entre os escores médios, em cada uma das dimensões, é indicada a utilização de testes de médias. Antes da utilização dos testes dessa natureza, é indicada a aplicação do teste de Kolmogorov-Smirnov (K-S). O teste K-S serve para analisar o ajustamento ou aderência à normalidade da distribuição de uma variável de nível ordinal ou superior, através da comparação das frequências relativas acumuladas observadas com as frequências relativas acumuladas esperadas (PESTANA; GAGEIRO, 2008).

Caso o teste K-S indique aderência à distribuição normal, devem ser utilizados testes paramétricos (MAROCO, 2007). Por outro lado, se for uma distribuição não-normal, deve-se optar por testes não paramétricos.

Confirmando-se o pressuposto da não-normalidade das distribuições, optou-se por aplicar o teste não paramétrico U de Mann-Whitney para amostras independentes. A técnica estatística de Mann-Whitney "é o teste não paramétrico adequado para comparar as funções de distribuição de uma variável pelo menos ordinal medidas em duas amostras independentes" (MAROCO, 2007, p.219). O referido teste permite ao pesquisador testar a distribuição, mesmo que um dos grupos possua tamanho amostral pequeno ou que não possua dados normalmente distribuídos (FÁVERO et al., 2009).

Foi realizado, então, um teste bilateral, com nível de significância $\alpha=0,05$, tendo sido adotado as seguintes hipóteses estatísticas:

H0: os dois grupos possuem percepções iguais sobre habilidades e competências.

H1: os dois grupos possuem percepções diferentes sobre habilidades e competências.

A decisão de rejeição ou não das hipóteses testadas foi tomada com base no $p$ valor, que indica a probabilidade estimada de rejeição da hipótese nula. Como se admitiu um nível de significância 0,05 , qualquer p valor abaixo desse, rejeita-se H0.

\section{Análise e Discussão dos Resultados}

\subsection{O Teste de Evocação de Palavras}

No intuito de agrupar as palavras evocadas foi realizada uma categorização das expressões de acordo com as competências e habilidades do profissional contábil, que estão dispostas nos órgãos nacionais e internacionais da contabilidade, conforme pode ser observado na Tabela 1. 
Anderson de Oliveira Reis, Gislaine Aparecida S. Sediyama, Vinicius de Souza Moreira e Camila C. Moreira

Tabela 1 - Categorização das palavras evocadas

\begin{tabular}{|c|c|c|}
\hline Categorias & Palavras evocadas/Frequência & Total \\
\hline $\begin{array}{l}\text { Habilidades/Competências } \\
\text { pessoais }\end{array}$ & $\begin{array}{l}\text { Ética (56), responsabilidade (36), comprometimento (22), } \\
\text { profissionalismo (10), formação (9), estudos contínuos (9), honestidade } \\
\text { (8), atualização (7), proativo (5), dedicação (5), comunicação (5), } \\
\text { agilidade (5), transparência (4), disciplina (3), capacidade (2), vontade } \\
\text { (2), liderança (2), especialização (2), motivação (2), persistência (1), } \\
\text { determinação (1), criatividade (1), curiosidade (1), línguas estrangeiras } \\
\text { (1), habilidade (1), competência (2), requisitos (2). }\end{array}$ & 204 \\
\hline Conhecimentos & $\begin{array}{l}\text { Conhecimentos (41), legislação (10), tributação (4), perícia (2), retorno } \\
\text { (2), finanças (2), custos (1), humanas (1), exatas (1), sociais (1), regime } \\
\text { de competência (1), apuração (1), normas contábeis (1), auditoria (1), } \\
\text { normas contábeis (1), auditoria (1). }\end{array}$ & 69 \\
\hline $\begin{array}{l}\text { Habilidades/Competências } \\
\text { funcionais }\end{array}$ & $\begin{array}{l}\text { Organização (36), técnica (12), análise (3), eficiência (3), } \\
\text { desenvolvimento (1), receitas }(1) \text {, burocracia }(1) \text {, lançamentos } \\
\text { sintetização (1), obrigações (1), mensuração (1). }\end{array}$ & 61 \\
\hline $\begin{array}{l}\text { Habilidades/Competências } \\
\text { relacionadas ao negócio }\end{array}$ & $\begin{array}{l}\text { Prática (5), Senso crítico (4), visão (3), gerenciamento (3), experiência } \\
\text { (3), qualidade (3), administração (2), planejamento (2), controle (1), } \\
\text { domínio (1). }\end{array}$ & 27 \\
\hline Habilidades intelectuais & $\begin{array}{l}\text { Raciocínio lógico (12), precisão (4), decisão (3), credibilidade (2), } \\
\text { objetividade (1). }\end{array}$ & 22 \\
\hline $\begin{array}{l}\text { Habilidades de comunicação } \\
\text { e interpessoais }\end{array}$ & $\begin{array}{l}\text { Interpretação (6), informação (4), relação interpessoal (1), diretrizes } \\
\text { (1). }\end{array}$ & 12 \\
\hline \multicolumn{2}{|l|}{ Total de palavras evocadas } & 395 \\
\hline
\end{tabular}

As habilidades e competências pessoais apresentam-se como os mais importantes para os discentes, uma vez que foram as mais evocadas (204 vezes). Isso significa que mesmo inconscientemente, os sujeitos da pesquisa valorizam mais as habilidades e competências pessoais, pois estas constituem o universo semântico dos discentes. A diferença das frequências entre as palavras dessas categorias e as demais reforça essa ideia.

Assim, as habilidades e competências pessoais constituem o núcleo central da representação social estudada. O conhecimento do núcleo central da representação social propicia maior clareza a respeito da visão dos discentes com relação às habilidades e competências. Dessa forma, tem-se que de maneira cognitiva as habilidades e competências pessoais, mesmo que de forma inconsciente, são as mais valorizadas pelos discentes.

A segunda categoria com maior frequência de evocação foi habilidades do conhecimento, seguida de habilidades e competências funcionais e relacionadas ao negócio e por último as habilidades interpessoal e intelectual. Isso significa que estas habilidades e competências tem importância secundária no universo semântico dos discentes. Destaca-se que esses resultados não indicam que os discentes desvalorizem essas habilidades e competências na atuação do contador, elas apenas possuem cotação secundária na percepção daqueles.

Os resultados apontam que, na percepção dos discentes, a comunicação, os comportamentos e atitudes que contribuem para forma como indivíduos se relacionam com os demais e o auto aprendizado, assim como o comportamento ético são as características de maior importância na atuação do profissional contábil. 


\subsection{Análise das Habilidades e Competências Exigidas pelo CNE, IFAC e AICPA}

Com o intuito de testar a confiabilidade das variáveis componentes de cada dimensão utilizou-se a técnica do Alfa de Cronbach. Verificam-se na Tabela 2 os resultados para o referido procedimento estatístico.

Tabela 2 - Alfa de Cronbach das dimensões

\begin{tabular}{lc}
\hline Dimensão & Alfa de Cronbach \\
\hline Habilidades e Competências Técnicas e Funcionais & 0,605 \\
Habilidades e Competências Pessoais & 0,715 \\
Habilidades Intelectuais e do Conhecimento & 0,702 \\
Habilidades e Competências Organizacionais e Relação Interpessoal. & 0,749 \\
\hline
\end{tabular}

Fonte: Resultados da pesquisa

Observa-se que todas as dimensões obtiveram valores do alfa superiores a 0,60 mostrando que são relevantes. Tais resultados determinaram que os constructos refletiram com confiabilidade suas respectivas variáveis.

Confirmando-se o pressuposto da não normalidade das distribuições, procedeu-se ao teste U de Mann-Whitney com o intuito de verificar se havia diferenças estatísticas entre os dois grupos.

Os resultados apontam que, com relação as dimensão Habilidades e Competências Técnicas e Funcionais, há diferença estatística entre os dois grupos formados ( $\mathrm{p}$ valor $<0,05$ ), conforme pode ser observado na Tabela 3.

Tabela 3 - Habilidades e Competências Técnicas e Funcionais

\begin{tabular}{ccccccccc}
\hline Dimensão & Grupo & $\mathbf{N}^{\mathbf{a}}$ & $\mathbf{\%}^{\mathbf{b}}$ & Mín. & Máx. & Média & $\boldsymbol{\sigma}^{\mathbf{c}}$ & p valor $^{\mathbf{d}}$ \\
\hline Habilidades e Competências & $2^{\mathbf{o}}$ e $4^{\mathbf{o}}$ períodos & 63 & 47,0 & 3,43 & 5,00 & 4,19 & 0,3635 & \multirow{2}{*}{0,034} \\
Técnicas e Funcionais & $6^{\mathbf{o}}$ e $8^{\mathbf{o}}$ períodos & 7 & 53,0 & 3,14 & 5,00 & 4,06 & 0,4149 & \\
\hline
\end{tabular}

Nota: ${ }^{a}$ Respondentes; ${ }^{b}$ Proporção dos respondentes; ${ }^{c}$ desvio padrão; ${ }^{d}$ p valor para o teste $U$ de Mann-Whitney. Fonte: Resultados da pesquisa.

Estes resultados sugerem que a percepção dos alunos com relação às habilidades e competências técnicas e funcionais mudam durante o curso de graduação, ou seja, aqueles que estão iniciando o curso tem uma percepção diferente daqueles que estão concluindo. Sendo assim, observou-se que os iniciantes valorizam mais essas habilidades e competências técnicas e funcionais (média $=4,19$ ) do que aqueles que estão concluindo (média $=4,06$ ).

Essa mudança pode ser decorrente da visão que o estudante já traz imbricado em si da própria profissão, que muitas vezes na realidade concreta é visualizada como meramente técnica e não estratégica e gerencial, além do fato da estrutura curricular do curso em questão focar, em seu núcleo básico de formação, o desenvolvimento e aplicação das técnicas contábeis. A partir do $5^{\circ}$ período o discente desenvolve habilidades e competências diferenciadas pelo contato com conhecimentos multidisciplinares e com isso, reconhece que a atuação do profissional ultrapassa a dimensão técnica.

Os resultados referentes à dimensão Habilidades e Competências Pessoais são apresentados na Tabela 4. Como se pode observar, constatou-se que há diferenças entre os dois grupos de estudantes ( $\mathrm{p}$ valor $<0,05)$. 
Anderson de Oliveira Reis, Gislaine Aparecida S. Sediyama, Vinicius de Souza Moreira e Camila C. Moreira

Tabela 4 - Habilidades e Competências Pessoais

\begin{tabular}{ccccccccc}
\hline Dimensão & Grupo & $\mathbf{N}^{\mathbf{a}}$ & $\mathbf{\%}^{\mathbf{b}}$ & Mín. & Máx. & Média & $\boldsymbol{\sigma}^{\mathbf{c}}$ & p valor $^{\mathbf{d}}$ \\
\hline Habilidades e & $2^{\mathbf{o}}$ e $4^{\mathbf{o}}$ períodos & 63 & 47,0 & 2,83 & 5,00 & 4,03 & 0,4712 & \multirow{2}{*}{0,043} \\
Competências Pessoais & $6^{\mathrm{o}}$ e $8^{\mathrm{o}}$ períodos & 71 & 53,0 & 2,83 & 5,00 & 4,18 & 0,4780 & \\
\hline
\end{tabular}

Nota: ${ }^{a}$ Respondentes; ${ }^{b}$ Proporção dos respondentes; ${ }^{\mathrm{c}}$ desvio padrão; ${ }^{\mathrm{d}} \mathrm{p}$ valor para o teste $U$ de Mann-Whitney.

Fonte: Resultados da pesquisa.

Pela média de pontuação da dimensão verifica-se que os alunos que estão em fase de conclusão do curso valorizam mais as habilidades e competências pessoais para atuação do contador (média $=4,18$ ) que os alunos que estão no início do curso.

Nota-se, ao comparar os resultados das duas primeiras dimensões, que as diferenças de percepções entre ambos os grupos podem ser explicadas pelo grau de experiência e conhecimentos adquiridos ao longo da graduação e pela estrutura curricular do curso oferecido pela instituição em análise.

No primeiro caso tem-se que os iniciantes, ainda com contato incipiente com o curso e suas oportunidades, tendem a valorizar mais os aspectos práticos e funcionais. Os concluintes, por sua vez, também os valorizam, porém, devido a um arcabouço maior de experiências (tanto acadêmicas quanto profissionais) valorizam mais as habilidades e competências pessoais.

No segundo caso, como a própria estrutura curricular do curso em análise oferta ao estudante à possibilidade de, a partir do $5^{\circ}$ período, escolher quais disciplinas gostaria de cursar (ou em outro olhar, quais habilidades e competências o discente gostaria de desenvolver), além daquelas fundamentais e obrigatórios para o exercício de sua profissão, pode ser uma das explicações para o fato dos concluintes considerarem as habilidades e competências pessoais como sendo a mais relevante para o exercício da profissão.

Com relação a dimensão Habilidades e Competência Intelectuais os resultados são apresentados da Tabela 5 .

Tabela 5 - Habilidades Intelectuais e do Conhecimento

\begin{tabular}{ccccccccc}
\hline Dimensão & Grupo & $\mathbf{N}^{\mathbf{a}}$ & $\mathbf{\%}^{\mathbf{b}}$ & Mín. & Máx. & Média & $\boldsymbol{\sigma}^{\mathbf{c}}$ & p valor $^{\mathbf{d}}$ \\
\hline $\begin{array}{c}\text { Habilidades Intelectuais e do } \\
\text { Conhecimento }\end{array}$ & Integral & 134 & 100 & 3,13 & 5,00 & 4,42 & 0,3650 & 0,993 \\
\hline
\end{tabular}

Nota: ${ }^{a}$ Respondentes; ${ }^{b}$ Proporção dos respondentes; ${ }^{c}$ desvio padrão; ${ }^{\mathrm{d}} \mathrm{p}$ valor para o teste $U$ de Mann-Whitney. Fonte: Resultados da pesquisa.

Os resultados apontam que não há diferenças estatísticas entre os dois grupos ( $\mathrm{p}$ valor $>0,05)$. Sendo assim, não há diferença entre a percepção dos discentes que estão iniciando e concluindo a graduação com relação à importância das habilidades intelectuais e do conhecimento para atuação do profissional contábil.

Para a dimensão Habilidades e Competências Organizacionais e Relação Interpessoal os resultados são apresentados na Tabela 6. 
Tabela 6 - Habilidades e Competências Organizacionais e Relação Interpessoal

\begin{tabular}{ccccccccc}
\hline Dimensão & Grupo & $\mathbf{N}^{\mathbf{a}}$ & $\mathbf{\%}^{\mathbf{b}}$ & Mín. & Máx. & Média & $\boldsymbol{\sigma}^{\mathbf{c}}$ & p valor $^{\mathbf{d}}$ \\
\hline $\begin{array}{c}\text { Habilidades e Competências } \\
\text { Organizacionais e Relação } \\
\text { Interpessoal }\end{array}$ & Integral & 134 & 100 & 2,57 & 5,00 & 4,22 & 0,4558 & 0,326 \\
\hline
\end{tabular}

Nota: ${ }^{a}$ Respondentes; ${ }^{b}$ Proporção dos respondentes; ${ }^{c}$ desvio padrão; ${ }^{\mathrm{d}} \mathrm{p}$ valor para o teste $U$ de Mann-Whitney.

Fonte: Resultados da pesquisa.

O p valor superior a 0,05 indica que não há diferença estatística entre os grupos de sujeitos analisados. Assim, pode-se inferir que tanto os discentes iniciantes como os concluintes da graduação atribuem, em média, o mesmo grau de importância para as habilidades e competências organizacionais e relação interpessoal para a atuação do contador.

A análise comparativa de todas as dimensões aponta que os alunos conferem maior importância às habilidades intelectuais e do conhecimento para a atuação do contador, uma vez que esta foi a dimensão com maior média (média $=4,42$ ). Observa-se que este resultado é diferente do teste de evocação de palavras que apresentou como categoria mais valorizada as habilidades e competências pessoais.

Contudo, destaca-se que apesar das habilidades intelectuais e do conhecimento possuírem maior importância pela percepção discente, as outras dimensões apresentaram médias maiores que 4,00, o que indica atribuição de elevado grau de importância.

\subsection{Construção da Imagem Simbólica}

A partir da análise da frequência das palavras evocadas e da determinação do núcleo central da representação estudada, pôde-se estabelecer a expressão e simbolização que os discentes possuem com relação às habilidades e competências necessárias a atuação do contador, uma vez que o teste de evocação de palavras capta o senso comum a respeito da expressão indutora.

Para captar a construção e a interpretação que os discentes formam do profissional contábil foi utilizado o grau de importância que eles atribuem a cada competência necessária ao contador, conforme estabelecido no CNE, IFAC e AICPA, já que eles se utilizam do conhecimento científico para analisar a importância de cada habilidade.

Tais aspectos fundamentam a imagem construída do profissional contábil pelos discentes, conforme demonstrado na Figura 2.

Figura 2- Construção da imagem simbólica da profissão contábil.

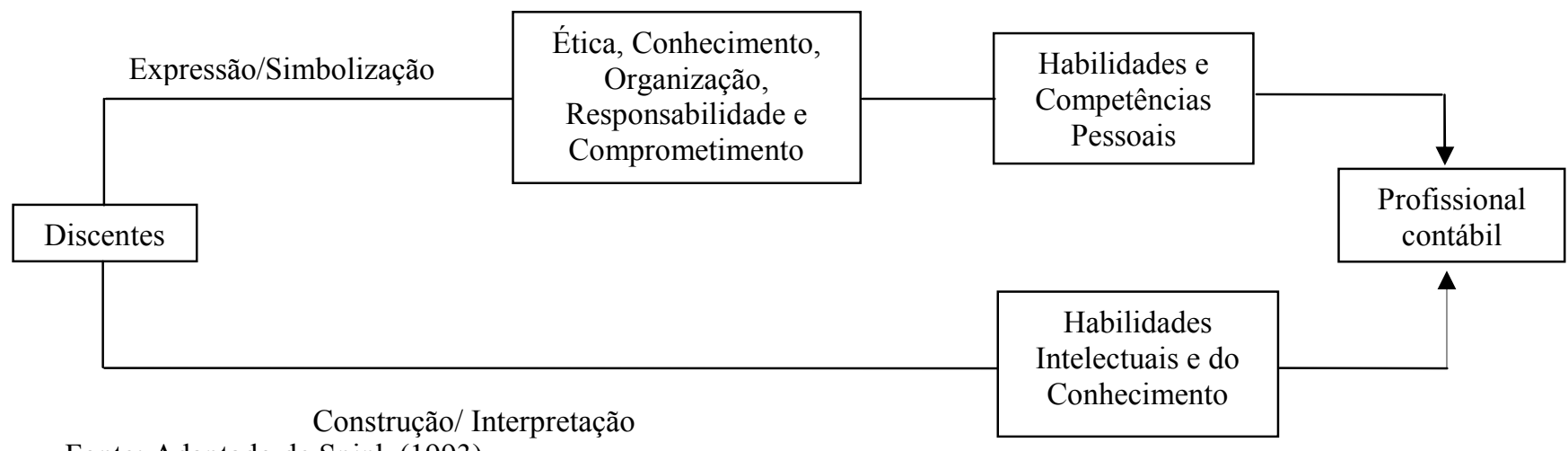

Fonte: Adaptado de Spink (1993). 
A construção da imagem que os discentes (sujeito) fizeram sobre o profissional contábil (objeto) foi formada por meio de duas vias: uma que é do conhecimento científico, apreendido durante a graduação e a outra do senso comum, o saber da comunidade.

A representação social foi apresentada pelas palavras evocadas: ética, conhecimento, organização, responsabilidade e comprometimento, sendo que estas representam as habilidades e competências pessoais que os discentes consideram serem as mais importantes para a atuação do profissional contábil, considerando como sistema de referência o senso comum.

As habilidades intelectuais e do conhecimento foram as que receberam maior grau de importância considerando a segunda via de construção da representação social, que está relacionada com o conhecimento científico. A construção desta representação corresponde à interface entre a realidade tida como concreta e a modificação dos sistemas de crenças e valores do sujeito a partir das condições conjunturais e de conhecimento a qual está submetido durante um curso de graduação.

Portanto, a representação social que os discentes formaram foi de um profissional que deve ter como principal característica o desenvolvimento de habilidades e competências pessoais, ou seja, o contador, na percepção discente, deve ser dotado de condutas éticas, de conhecimento teórico tanto em sua área como nas afins, organização para executar o trabalho, responsabilidade nas suas ações e comprometimento com a profissão. E, também, de habilidades intelectuais e do conhecimento para o exercício da profissão contábil.

\section{Considerações Finais}

Este estudo teve por objetivo identificar a percepção dos discentes do curso de Ciências Contábeis de uma Instituição pública de Ensino Superior de Minas Gerais, sobre as habilidades e competências necessárias para a atuação do profissional contábil.

Diante dos resultados da pesquisa, verificou-se que a representação social que os discentes formaram foi de um profissional que deve ter como principal característica o desenvolvimento de habilidades e competências pessoais. O contador, na percepção discente, deve ser dotado de condutas éticas, de conhecimento teórico tanto em sua área como nas afins, organização para executar o trabalho, responsabilidade nas suas ações e comprometimento com a profissão.

Pôde-se constatar que há diferentes formas de produzir a imagem da profissão contábil, visto que, cada estudante já tinha uma representação do que a profissão contábil representava para eles antes mesmo de ingressar na universidade, mas no decorrer do curso foram sendo formadas outras imagens, percepções que só foram capazes de fazer após o ingresso.

As habilidades e competências técnicas e funcionais mostraram que os iniciantes valorizam mais estas do que os já estavam concluindo, enquanto as habilidades e competências pessoais são mais valorizadas pelos estudantes da fase de conclusão do que para os iniciantes.

Por outro lado, as habilidades e competências relacionadas aos negócios e as habilidades de comunicação e interpessoais, assim como habilidades intelectuais e do conhecimento não tiveram diferenças entre os grupos de ingressos e de concluintes. Associa- 
se a este resultado fato de que as percepções que os estudantes tinham ao ingressar no curso são similares as que possuem durante a graduação, não demostrando diferenças relevantes.

As habilidades e competências que os discentes apontaram como as mais importantes são também as mais demandadas pelo mercado de trabalho, pois estudos realizados por Cardoso, Souza e Almeida, (2006), Leal, Soares e Sousa, (2008) e Pires, Ott e Damacena, (2010) revelaram que as habilidades pessoais são uma das mais requeridas pelos empregadores, como a liderança, proatividade, motivação, comunicação, comportamento ético, entre outros. Assim como conhecimentos na área, como contábil, fiscal, tributária, auditoria, e outros e as habilidades e competências técnicas como interpretar cenários, avaliar processos e resultados, solucionar problemas dentre outros.

A contribuição o estudo está no fato de revelar que a construção social dos discentes está vinculada não só aos conhecimentos que traz em si de sua interseção cultural cotidiana, mas que sua percepção pode ser modificada a partir da forma como se estrutura curricularmente um curso, quando esta lhe oferece flexibilidade na escolha de quais habilidades e competências além daquelas básicas e fundamentais requeridas para o exercício da profissão ele quer desenvolver, e de como se dá o processo de infusão de conhecimentos e valores a partir de um contexto social maior, que no caso seria a amplitude do campo de atuação do contador.

Como estudo futuros, propõe-se a ampliação deste estudo para instituições cuja estrutura curricular apresente diferenças em relação àquela adotada pela instituição em análise para que, a partir disso, seja possível verificar a relação desta variável com a construção social dos discentes em relação à profíssão contábil.

\section{Referências Bibliográficas}

ABRIC, J.C.. Les representations sociales: aspects théoriques. In: Abric, J.C. (Dir.). Pratiques sociales et representations. 3e éd. Paris: PUF, p. 11-36, 2008.

ALVES-MAZZOTTI, A. J.. Representações sociais: aspectos teóricos e aplicações à educação. Revista Múltiplas Leituras, 1(1), 18-43, 2008.

AICPA - American Institute of Certified Public Accountants. Mapping of the Core Competency Framework to the Skills Tested on the CPA Exam. New York: AICPA. 2010. Disponível em: < http://www.aicpa.org/>. Acesso em: 30 nov. 2013.

BISQUERRA, R.; SARRIERA, J. C.; MARTÍNEZ, F.. Introdução à estatística. Porto Alegre: Artmed, 2004.

BRASIL. Resolução CNE/ CES no . 10, de 16 de dezembro de 2004. Disponível em: $<$ http://portal.mec.gov.br/cne/arquivos/pdf/rces10_04.pdf $>$. Acesso em 9 out. 2013. 
CARDOSO, R. L.; RICCIO, E. L.; ALBUQUERQUE, L. G.. Competências do contador: um estudo sobre a existência de uma estrutura de interdependência. Revista de Administração da Universidade de São Paulo. 44(4), 365-379, 2009.

CARDOSO, R. L.; RICCIO, E. L.; MENDONÇA NETO, O. R.; OYADOMARI, J. C.. Entendo e explorando as competências do contador gerencial: uma análise feita pelos profissionais. Advances in Scientific and Applied Accounting, 3(3), 353-371, 2011.

CORY, S.; HUTTENHOFF, T.. Perspectives of non-public accountants about accounting education and certifications: An exploratory investigation. Journal of Finance and

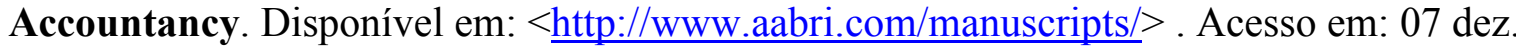
2013.

CRAMER, L.; BRITO, M. J.; CAPPELLE, M. C. A.. As Representações Sociais das Relações de Gêneros na Educação Superior: a Inserção do Feminino no Universo Masculino. Anais do Encontro da Associação Nacional dos Programas de Pós-Graduação em administração, Campinas-SP, Brasil, 2001.

DUTRA, J. S.. Competências: Conceitos e Instrumentos para a Gestão de Pessoas na Empresa Moderna. São Paulo: Atlas, 2004.

FARR, R. M.. Representações sociais: a teoria e sua história In: GUARESCHI, P. e JOVCHELOVITCH, S. (orgs.). Textos em representações sociais. 7ed. Petrópolis: Vozes, 2002.

FÁVERO, L. P.; BELFIORE, P.; SILVA, F. L.; CHAN, B. L.. Análise de dados: modelagem multivariada para tomada de decisões. Rio de Janeiro: Elsevier, 2009.

FERREIRA, V. C. P.. ONGs no Brasil: um estudo sobre suas características e fatores que têm induzido seu crescimento. Tese de Doutorado. Fundação Getúlio Vargas, Rio de Janeiro, RJ, Brasil, 2005.

FLEURY, A.; FLEURY, M. T. L.. Estratégias empresariais e formação de competências: um quebra-cabeça caleidoscópio da indústria brasileira. 3.ed. São Paulo: Atlas, 2004.

FRANCO, M. L. P. B.. Representações sociais, ideologia e desenvolvimento da consciência. Cadernos de Pesquisa, 121(34), 169-186, 2004.

GOMES, D. M.. Competências e habilidades do diretor. Campo Grande, MS: UCDB, 2003. 
HAIR JR., J. F.; BLACK, B.; BABIN, B.; ANDERSON, R. E.; TATHAM, R. L.. Análise Multivariada de Dados. Porto Alegre: Bookman, 2009.

HAIR, J. F.; BABIN, B.; MONEY, A. H.; SAMUEL, P.. Fundamentos de métodos de pesquisa em administração. Porto Alegre: Bookman, 2005.

IFAC - International Federation Of Accountants. Handbook of International Education Pronouncements 2010 Edition. New York, 2013. Disponível em:

$<$ http://www.ifac.org/sites/default/files/publications/files/handbook-of-international-e-2.pdf $>$. Acesso em: 30 nov. 2013.

IFAC - International Federation Of Accountants. Strategy and Work Plan. New York, 2010 April. Disponível em: < http://www.ifac.org/sites/default/files/>. Acesso em: 30 nov. 201.

JODELET, D.. As representações sociais. Rio de Janeiro: EdUERJ, 2001.

LEAL, E. A.; SOARES, M. A.; SOUSA, E. G. de.. Perspectivas dos Formandos do Curso de Ciências Contábeis e as Exigências do Mercado de Trabalho. Revista Contemporânea de Contabilidade, 10(1),147-159, 2008.

MAGALHÃES, E. M. M.; MAIA, H.. O trabalho docente por professores de curso de pedagogia. Revista Múltipla Leituras, 1(2), 189-206, 2009.

MAROCO, J.. Análise Estatística com Utilização do SPSS. $3^{\mathrm{a}}$ ed. Lisboa: Ś́labo, 2007.

MAZZOTTI, T. B.. Representações sociais de problemas ambientais: uma contribuição à educação brasileira. In: Moreira, A. P. (org.). Representações sociais: teoria e prática. João Pessoa: UFPB, 2001.

MOHAMED, E. K.; LASHINE, S. H.. Accounting knowledge and skills and the challenges of a global business environment. Managerial Finance, 29(7), 3-16, 2003.

MOSCOVI, S.. A Representação social da psicanálise. Rio de Janeiro: Zahar, 1978.

MOSCOVI, S.. Representações sociais: investigações em psicologia social. 2 ed. Petrópolis: Vozes, 2004.

MUNHOZ, I. M. S.. Educação para a carreira e representações sociais de professores: limites e possibilidades na educação básica. Tese de Doutorado. Universidade de São Paulo, Ribeirão Preto, SP, Brasil, 2010. 
OTT, E.; CUNHA, J. V. A.; CORNACHIONE JUNIOR, E. B.; Luca, M. M. M.. Relevância dos conhecimentos, habilidades e métodos instrucionais na perspectiva de estudantes e profissionais da área contábil: estudo comparativo internacional. Anais do Encontro da Associação Nacional dos Programas de Pós Graduação em Ciências Contábeis, VitóriaES, Brasil, 2011.

PESTANA, M. H.; GAGEIRO, J. N.. Análise de dados para ciências sociais a complementaridade do SPSS. 5. ed. Lisboa: Sílabo, 2008.

PIRES, C. B.; OTT, E.; DAMACENA, C.. A formação do contador e a demanda do mercado de trabalho na região metropolitana de Porto Alegre (RS). Revista de Administração e Contabilidade da Unisinos, 7(4), 315-327, 2010.

SÁ, C. P. Núcleo central das representações sociais. Rio de Janeiro: EdUERJ, 1998.

SAMPIERI, R. H.; COLLADO, C. F.; LUCIO, P. B.. Metodologia de Pesquisa, 3.ed, São Paulo: McGraw-Hill, 2006.

SANTANA, G. A. S.; REIS, A. O.; REIS, M. C. T.; TAVARES, B. A Representação Social na Interpretação de um Sonho de Cidade Coletivamente Construído. Revista Administração Pública e Gestão Social, 5(1), 21-27, 2013.

SCHLINDWEIN, A. C.. O ensino de Ciências Contábeis nas Instituições de Ensino da Mesorregião do Vale do Itajaí/SC: uma análise das contribuições curriculares da Resolução CNE/CES N. 10/2004. Dissertação de Mestrado, Universidade Regional de Blumenau, Blumenau, SC, Brasil, 2007.

SPINK, M. J. P. O Conceito de Representação Social na Abordagem Psicossocial. Cadernos de Saúde Pública, 9 (3), 300-308, 1993.

VERGARA, S. C. Métodos de pesquisa em administração, ed. Atlas, 4.ed. São Paulo, 2010.

VERGARA, S. C.; FERREIRA, V. C. P. A representação social de ONGs segundo formadores de opinião do município do Rio de Janeiro. Revista de Administração Pública, 39(5), $1137-1159,2006$. 